Journal of Energy and
Environmental Sustainability
Journal homepage : www.jees.in

\title{
Low Temperature Combustion Engines and Mode Switching Strategies - A review
}

\author{
Akhilendra Pratap Singh, Avinash Kumar Agarwal \\ Engine Research Laboratory, Department of Mechanical Engineering, Indian Institute of Technology Kanpur, Kanpur-208016, India
}

\section{A R T I C L E I N F O}

Received : 22 November 2018

Accepted : 06 December 2018

Keywords:

Low temperature combustion (LTC);

Mode switching; Particulate matter (PM);

Oxides of nitrogen $\left(\mathrm{NO}_{x}\right)$; Reactivity

controlled compression ignition (RCCI).

\begin{abstract}
A B S T R A C T
Rapidly increasing fossil fuel demand and deteriorating air quality have resulted in enormous pressure on automotive researchers and OEMs to develop more efficient and clean internal combustion (IC) engines. Low temperature combustion (LTC) strategies have shown significant potential of reducing oxides of nitrogen (NOx) and particulate matter (PM) emissions simultaneously without any performance sacrifice. In last few decades, researchers have resolved many issues of LTC however it's full-load application, even in light-duty engines, has not been experimentally demonstrated until now due to lack of control over ignition timing and heat release rate (HRR). This limits the commercial application of various LTC technologies in production-grade engines. To tackle this problem, an intermediate solution namely 'mode switching technique' has been demonstrated. In mode switching technique, engine operates in LTC mode up to medium loads and then switches to conventional compression ignition (CI) combustion mode to cater to higher engine loads. This dual mode combustion seems to be an effective solution for commercializing the LTC technology. This article discusses different strategies of mode switching in gasoline and diesel engines and exhibits its potential in IC engines. Use of reactivity controlled compression ignition (RCCI) combustion as LTC derivative in mode switching technique may be a future research area for development of next generation road transport vehicles.
\end{abstract}

\section{Introduction}

Internal combustion (IC) engines are indispensable for the evolution and existence of modern society. Majority of engines powered vehicles today use reciprocating piston powered by combustion of petroleum products. Most commonly used engines include spark ignition (SI) and compression ignition (CI) engines. However these engines are facing several challenges namely extensive dwindling of limited fossil fuel reserves and harmful emissions affecting the environment as well as the human health. Environmentalists and policy makers have suggested that global fuel consumption and harmful emissions can be reduced by partial or full replacement of IC engines, which is extremely challenging and unfeasible as of now. Therefore, researchers are attempting to develop more efficient and cleaner IC engines compared to current generation IC engines.

Considering environmental factors, IC engines contribute extensively to ambient air pollution. Carbon monoxide (CO) and unburned hydrocarbons (UHCs) emitted by IC engines in addition to Carbon dioxide $\left(\mathrm{CO}_{2}\right)$ contribute to issues such as global warming. Engine generated nitrogen oxides (NOx) and UHCs react with atmospheric gases to produce photochemical smog. Particulate Matter (PM), especially from diesel engines is another major concern of current generation engine technology, which is significantly increasing the health issues among urban population. Figure 1 shows different species emitted by IC engines and associated health and environmental effects.

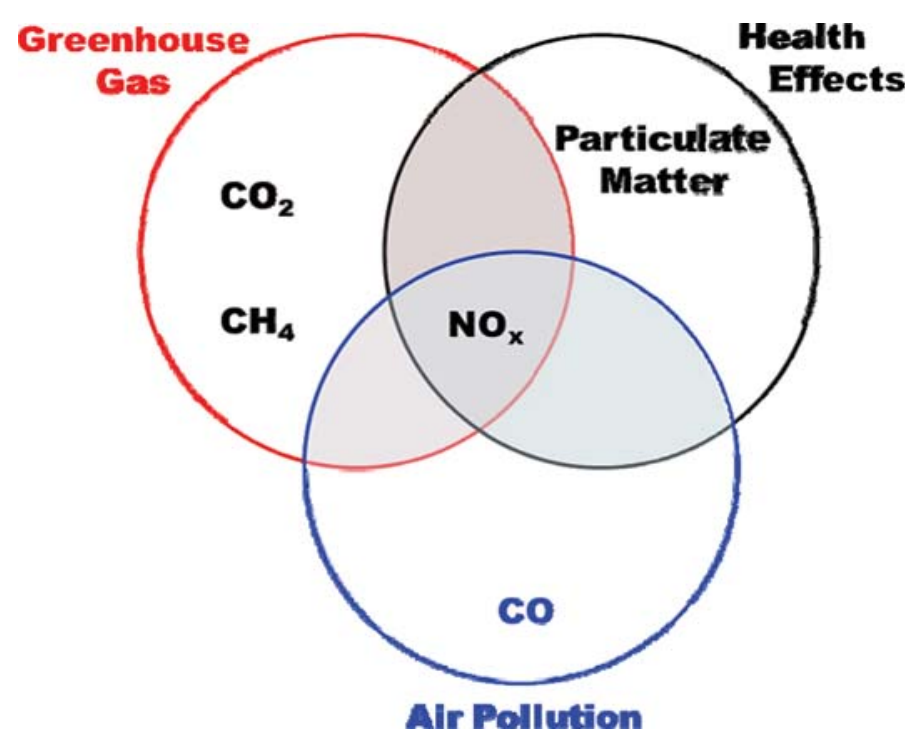

Figure 1: Engine exhaust emissions and associated health and environmental effects

\footnotetext{
*Corresponding Author: akag@iitk.ac.in
} 
To control these pollutants, environmental protection agencies have adopted stringent emission standards globally for simultaneous reduction of PM and NOx emissions primarily along with other gaseous pollutants. In order to meet these stringent requirements, use of novel combustion modes such as low temperature combustion (LTC) should be considered. LTC has been experimentally proven to produce lower emissions, while maintaining fuel efficiency at the same level as conventional engines.

\section{Low Temperature Combustion}

Conventional diesel combustion is characterized by heterogeneous combustion, which creates high temperature regions (responsible for higher NOx) and locally fuel-rich regions (responsible for PM formation). LTC strategies have gained substantial attention due to their potential to overcome the PM-NOx trade-off simultaneously. LTC is a general term used for advanced combustion strategies, and it has several derivatives namely homogeneous charge compression ignition (HCCI), reactivity controlled compression ignition (RCCI) and premixed charge compression ignition (PCCI) etc. [1].

Akihama et al. [2] explained the fundamental theory of LTC using local equivalence ratio vs. flame temperature curve (Figure 2). This figure also represents the PM-NOx dilemma associated with conventional CI combustion mode in which fuel-lean regions above $2200 \mathrm{~K}$ produce more NOx however fuel-rich regions above $1800 \mathrm{~K}$ produces the PM predominantly. In their study, they suggested two critical parameters namely adequate time for fuel-air mixing and low peak combustion temperature for simultaneous reduction of NOx and PM. They reported that LTC can be achieved at temperatures, which are significantly lower than the NOx formation window and local equivalence ratios required for LTC are way below soot formation window.

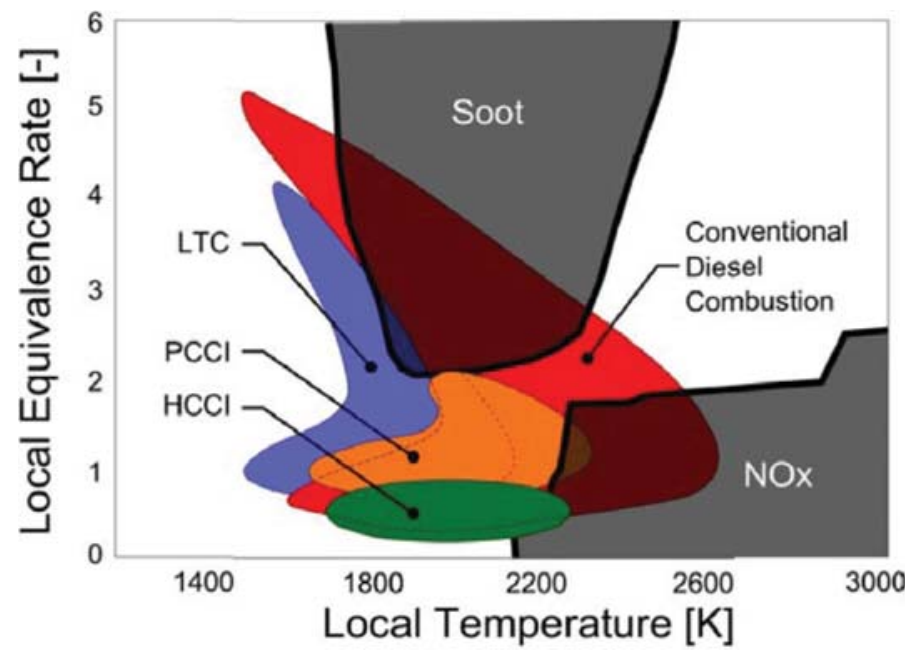

Figure 2: Local equivalence ratio-flame temperature correlation of different low temperature combustion techniques for simultaneous control of soot and NOx formation [1]

Kook et al. [3] also investigated the effects of charge dilution on diesel-fueled LTC using exhaust gas recirculation (EGR). They reported that charge dilution reduces the flame temperature and affects the local equivalence ratio due to lower oxygen concentration and longer ignition delay. They experimentally verified the effect of charge dilution on NOx and particulate formation reduction. However, this also enhanced the incomplete combustion product formation such as $\mathrm{CO}$ and $\mathrm{HC}$. To tackle this issue, different derivatives of LTC were demonstrated by various researchers, as discussed in the next section.

\section{LTC Strategies}

HCCI, PCCI and RCCI combustion are important LTC strategies. Important features of these LTC derivatives and their comparison with conventional combustion techniques are presented in figure 3.

\subsection{HCCI Combustion}

HCCI is one of the initial diesel combustion concepts, which combines advantages of CI (stratified charge compression ignition) and SI (homogeneous charge spark ignition) combustion modes because it uses premixed charge similar to that of SI mode however auto ignition happens similar to that of CI mode. This concept was initially proposed by Onishi

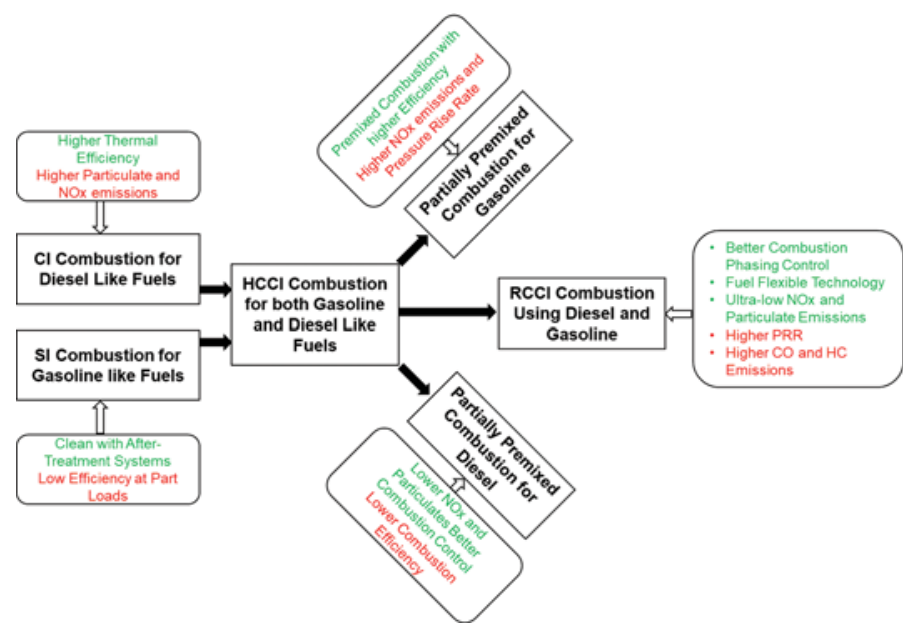

Figure 3: Different combustion strategies [4]

et al. [5], who applied it in a gasoline-fueled two-stroke engine with an objective of increasing combustion stability at part load conditions. His group named this combustion technique as "Active Thermo-Atmospheric Combustion" (ATAC). In HCCI combustion mode, fuel is injected significantly before the start of combustion (SoC) in the intake stroke. This ensures that sufficient time is available for homogeneous fuel-air mixture formation. This homogeneous mixture undergoes simultaneous combustion at multiple sites in the combustion chamber unlike SI (flame propagation) or CI (locally rich flame front) combustion modes. Here, combustion phasing is distinct from the injection timing and combustion is mainly controlled by chemical reaction kinetics. HCCI combustion was easily implemented in SI engines [6-7] however diesel-fueled HCCI engine development has several issues due to lower volatility of mineral diesel and cool combustion chemistry [1,8]. Gan et al. [9] and Dec and Kelly-Zion [10] used early and late fuel injection strategies for achieving diesel HCCI combustion however these strategies resulted in inferior combustion due to poor fuel-air mixing. Low volatility of diesel was found to be the main hurdle in achieving satisfactory demonstration of diesel HCCI. To enhance the fuel-air mixture quality, Ryan and Callahan [11] demonstrated external fuel-air mixture preparation technique and supplied diesel into the intake air stream. Singh et al. [12] developed a 'fuel vaporizer' to study the combustion, emission and performance characteristics of diesel and biodiesel-fueled HCCI combustion. These studies reported superior emission characteristics of HCCI combustion compared to conventional CI combustion mode however this technique suffered from lack of combustion control, higher HRR, and higher levels of $\mathrm{HC}$ and $\mathrm{CO}$ emissions, which limited its application, particularly at higher engine loads.

\subsection{PCCI Combustion}

PCCI combustion is almost similar to HCCI combustion and this can be easily implemented in modern common rail direct injection (CRDI) diesel engines. In PCCI combustion, lean-premixed fuel-air mixture is compression-ignited in order to avoid locally rich as well as high temperature regions, where soot and NOx formations are high. PCCI combustion results in emission characteristics quite similar to $\mathrm{HCCI}$ combustion, however it offers better control over the combustion events. In PCCI combustion, important combustion parameters such as ignition delay, combustion duration etc. can be controlled by controlling in-cylinder charge motion, compression ratio, fuel injection parameters and EGR Jain et al. [13-14] carried out detailed investigations of PCCI combustion and developed an optimized fuel injection strategy. They used multiple injections along with EGR and observed lower NOx reduction and PM emissions due to EGR and multiple injections, respectively. Multiple fuel injection strategy showed significant effect on the fuel-air mixture homogeneity and optimum EGR reduced the in-cylinder temperature below the NOx formation threshold. Despite these advantages, PCCI combustion could not be implemented in commercial engines so far due to lack of control over combustion events at higher engine loads. Presence of large fuel quantity at high engine load leads to high HRR, which can potentially damage the engine components.

\subsection{RCCI Combustion}

RCCI combustion technique was demonstrated for the first time at 
Engine Research Center, University of Wisconsin, Madison, USA [15]. RCCI combustion has evolved as a dual-fuel technique, wherein a lowreactivity fuel (such as gasoline/ alcohols/ compressed natural gas (CNG)) is supplied via port fuel injection (PFI) or by using early direct injection (DI) to create a homogeneous fuel-air mixture. To control the start of SoC, a high-reactivity fuel (such as mineral diesel/ biodiesel) is injected directly into the combustion chamber at optimized start of injection (SoI) timing. Due to this high reactivity fuel, combustion starts in high reactivity zones and then proceeds to low reactivity zones of the combustion chamber. In RCCI combustion, combustion parameters such as SoC, combustion duration, etc. can be controlled by the spatial stratification of fuel reactivities. The combustion duration is controlled by the reactivity gradient, which also affects pressure rise rates (PRR) as well as combustion noise. Low and high reactivity fuel quantities control the SoC, which advances with increasing relative fraction of high reactivity fuel. Dualfuel strategy allows easier control of combustion phasing. Combustion phasing is essentially controlled by localised concentration of highreactivity fuel and SoI timing of high-reactivity fuel. Table 1 shows the comparison of few LTC modes vis-a-vis conventional combustion modes.

Previous research includes different derivatives of LTC such as HCCI combustion, PCCI combustion and RCCI combustion for low-load applications in light-duty and heavy-duty engines. Though, LTC derivatives have shown significant potential in simultaneously reducing NOx and soot emissions, they bprimarily suffers from the issue of lack of combustion control, which leads to knocking combustion at high loads and misfire or unstable combustion at low loads (during engine start). These difficulties restrict the envelope of operation to narrow range and do not cater to all operating conditions. This narrow operational range of LTC is the main obstacle for its commercialization. Therefore several efforts were made by researchers to expand the operational range of LTC and for this, turbochargers, superchargers and multiple injection strategies were deployed, but it remained difficult for LTC to cover the entire operational range for commercial diesel engines. Based on these observations, it was concluded that for real world application of LTC and to extend its operating range to practical application domains, a more conventional diesel combustion mode would be needed for remaining areas of engine operation, where LTC is not possible. Since for high load range, simultaneous reduction of NOx and soot is not possible for LTC, CI mode has to be used to enhance the efficiency and fuel economy as far as possible. To tackle this problem, an intermediate solution namely 'mode switching technique' has been demonstrated. In mode switching technique, engine can operate in both LTC as well as CI combustion mode, depending on engine operating condition, and it is emerging as an effective solution for commercializing the LTC technology.

\section{Combustion Mode Switching}

A mode switching strategy is based on the objective to attain benefits offered by LTC at low engine loads, while switching to conventional CI/ SI combustion modes at higher loads. For a real mode switching engine, the engine operating parameters should be automatically adjusted to operate in suitable combustion mode at different engine loads.

\subsection{Combustion Mode Switching in SI Engines}

Initially, mode switching strategy has been implemented in gasoline engines. Santoso et al. [17], Milovanovic et al. [18], Zhang et al. [19] and Tian et al. [20] have successfully achieved combustion mode switching between SI combustion and LTC by controlling the amount of hot residual gas, employing variable valve actuation (VVA). In gasoline engines, negative valve overlap (NVO) was used to operate the engine in HCCI combustion mode however using the positive valve overlap (PVO), the engine could be operated in conventional SI combustion mode. They also emphasized on several other parameters namely throttle angle, fuelling rate and spark timing for achieving smooth combustion mode switching. Milovanovic et al. [18] reported that transition from SI to HCCI combustion does not affect drivability, however transition from HCCI to SI combustion results in abrupt changes in torque output and HC emissions. Weak combustion cycles and misfire due to the asynchrony of valve profile were the responsible factors for this behavior. This issue was addressed by Tian et al. [20]. They used stepped switch strategy, in which cam was operated in several steps. For HCCI to SI combustion mode switching, first the throttle was closed and then cam system was switched from NVO to normal cam profile for achieving SI combustion. In another study carried out by Kuboyama et al. [21], a blow-down supercharging system was used for combustion mode switching between SI and HCCI combustion modes.

Few researchers investigated the combustion mode switching between HCCI and SI combustion modes using spark assistance, which is known as spark assisted compression ignition (SACI). Manofsky et al. [22] reported that SACI combustion could be easily switched from HCCI combustion at low loads to SI combustion at high loads. They demonstrated SACI technique and achieved a maximum load of <"7.5 bar net mean effective pressure (NMEP). Polovina et al. [23] reported that fuel consumption of SACI combustion mode was $~ 5 \%$ lower than SI combustion mode along with significantly lower NOx emissions. Zhou et al. [24] performed experiments using HCCI, SACI and SI combustion modes in a high compression ratio DI engine (Figure 4).

Table 1: Comparison of SI, CI, HCCI, PCCI and RCCI combustion strategies [16]

\begin{tabular}{|c|c|c|c|c|c|}
\hline & SI & $\mathrm{CI}$ & $\mathrm{HCCI}$ & PCCI & RCCI \\
\hline Ignition type & Spark ignited & $\begin{array}{l}\text { Compression } \\
\text { ignited }\end{array}$ & $\begin{array}{l}\text { Compression } \\
\text { ignited }\end{array}$ & $\begin{array}{l}\text { Compression } \\
\text { ignited }\end{array}$ & $\begin{array}{l}\text { Compression } \\
\text { ignited }\end{array}$ \\
\hline Fuel type & High octane & High cetane & $\begin{array}{l}\text { Blend of liquid } \\
\text { or gaseous fuels }\end{array}$ & $\begin{array}{l}\text { Blend of liquid } \\
\text { or gaseous fuels }\end{array}$ & $\begin{array}{l}\text { PFI of high octane fuel } \\
\text { and DI of high cetane fuel }\end{array}$ \\
\hline $\begin{array}{l}\text { Power output } \\
\text { control }\end{array}$ & Air-flow control & Fuel-flow control & Fuel-flow control & Fuel-flow control & $\begin{array}{l}\text { Fuel reactivity } \\
\text { stratification }\end{array}$ \\
\hline $\begin{array}{l}\text { Fuel-air mixture } \\
\text { condition }\end{array}$ & $\begin{array}{l}\text { Near } \\
\text { stoichiometric } \\
\text { air-fuel ratio }\end{array}$ & Lean air-fuel ratio & $\begin{array}{l}\text { Lean air-fuel ratio } \\
\text { or charge dilution }\end{array}$ & $\begin{array}{l}\text { Lean air-fuel ratio or } \\
\text { high charge dilution }\end{array}$ & $\begin{array}{l}\text { Air-fuel ratio stratification, } \\
\text { typically without charge } \\
\text { dilution }\end{array}$ \\
\hline $\begin{array}{l}\text { Combustion control } \\
\text { mechanism }\end{array}$ & $\begin{array}{l}\text { Flame propagation } \\
\text { speed }\end{array}$ & $\begin{array}{l}\text { Time of fuel } \\
\text { vaporization and } \\
\text { mixing }\end{array}$ & $\begin{array}{l}\text { Chemical } \\
\text { kinetics }\end{array}$ & $\begin{array}{l}\text { Chemical kinetics and } \\
\text { injection timing }\end{array}$ & $\begin{array}{l}\text { Chemical kinetics and } \\
\text { fuel reactivity }\end{array}$ \\
\hline $\begin{array}{l}\text { Other emission } \\
\text { characteristics }\end{array}$ & Higher $\mathrm{CO}_{2}$ & Lower $\mathrm{CO}_{2}$ & $\begin{array}{l}\text { Higher } \mathrm{HC} \text { and } \\
\mathrm{CO} \text { and lower } \mathrm{CO}_{2}\end{array}$ & $\begin{array}{l}\text { Higher } \mathrm{HC} \text { and } \mathrm{CO} \\
\text { and lower } \mathrm{CO}_{2}\end{array}$ & $\begin{array}{l}\text { Very high } \mathrm{HC} \text { and } \mathrm{CO} \\
\text { (without after-treatment) } \\
\text { and lower } \mathrm{CO}_{2}\end{array}$ \\
\hline
\end{tabular}



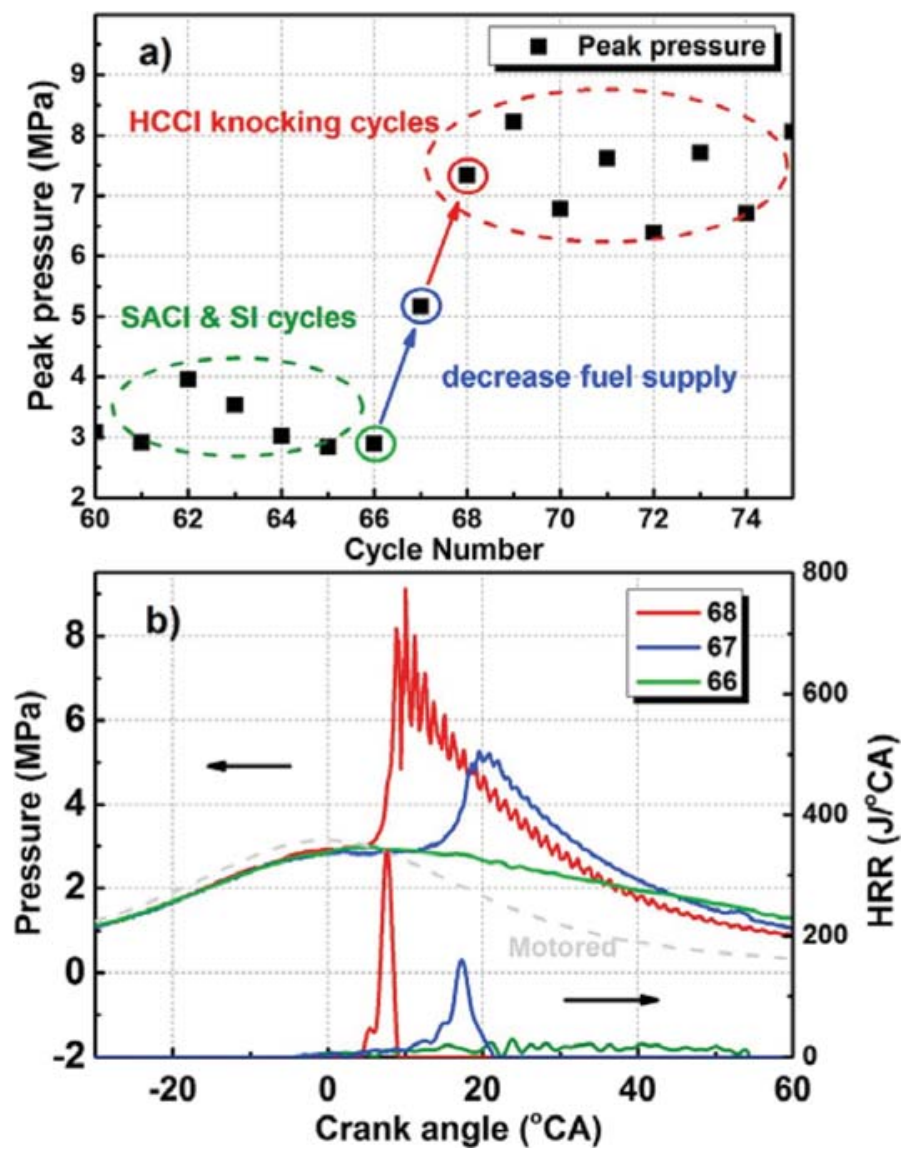

Figure 4: Transition from SACI to HCCI knock cycles [24]

They suggested a three-mode concept for smoother engine operation. Engine should be operated in HCCI combustion mode at lower loads, which can be switched to SACI combustion mode at medium engine loads and finally back in SI combustion mode at higher engine loads to avoid excessive PRR. They reported that internal EGR (I-EGR) and spark timing were the key parameters for switching the engine operation from one combustion mode to another. Fuel stratification was another important parameter to control the combustion and knock reduction. However, this technique was unable to lead to stable combustion mode transition from SACI and SI combustion modes (Figure 4).

\subsection{Combustion Mode Switching in CI Engines}

Previous studies on mode switching in diesel engines pointed out two important issues for mode switching between LTC and CI combustion modes. First issue is related to difference in fuel injection parameters. In PCCI combustion, fuel is injected very early at a high fuel injection pressure (FIP) for preparing homogeneous fuel-air mixture before SoC however in CI combustion, retarded SoI timings are used at medium FIP. This difference in injection parameters results in variation in engine power output during mode transition. Hence, fuel quantity injected per cycle remains variable for the same IMEP, which requires a complex fuel injection strategy, depending on mode of combustion. Second issue is related to the sensitivity for in-cylinder conditions. LTC modes are more sensitive to in-cylinder conditions compared to CI combustion mode. Therefore, slight variations in in-cylinder temperature and pressure may result in abnormal combustion (knocking or misfiring) during mode transition.

Narayanaswamy and Rutland [25] defined mode switching as the strategy during which there was a controlled change in engine operating parameters namely injection timing, FIP, quantity of fuel injected, duration of fuel injection and EGR level. For effective mode switching, these parameters should be changed gradually in order to avoid any sudden fluctuation in engine power output and exhaust emissions. During mode switching, rapid fluctuations in power output adversely affects drivability. Singh et al. [26] optimized fuel injection parameters and EGR to achieve mode switching between $\mathrm{CI}$ and PCCI combustion modes in a production engine (Figure 5). They reported that transition from CI to PCCI mode was relatively easier compared to transition from PCCI to CI combustion mode, which occured at relatively higher engine load. Singh and Agarwal [27] developed a mode switching prototype engine for mode switching characterisation of mineral diesel and diesohol (blend of ethanol with mineral diesel) (Figure 6)

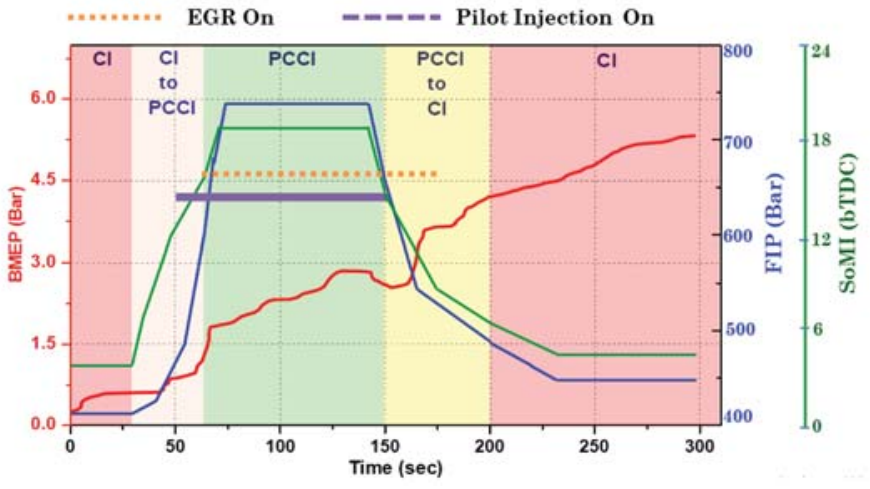

Figure 5: Fuel injection parameters and EGR for CI and PCCI combustion mode switching

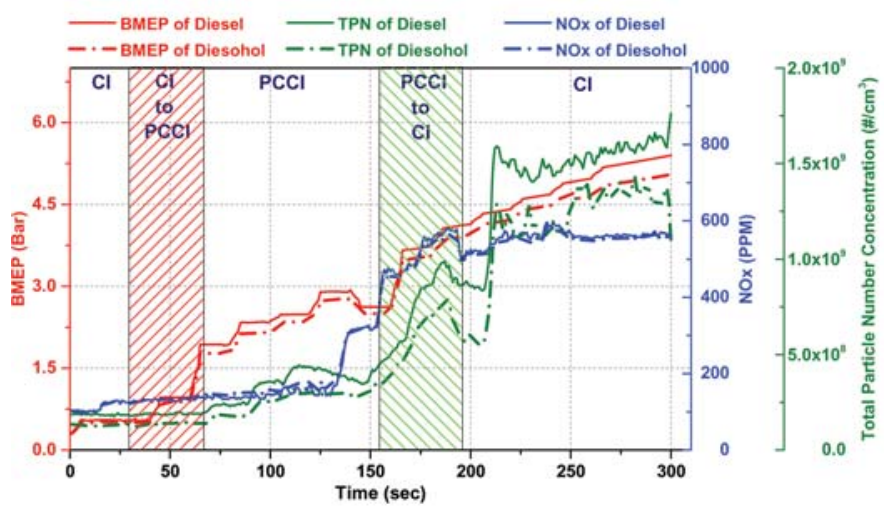

Figure 6: Variations in NOx and TPN emissions with BMEP during different combustion modes and mode transitions [27]

combustion mode to another. Using this technique, they achieved $6.5 \mathrm{bar}$ NMEP in a commercial diesel engine. They reported lower particulate number emissions from diesohol-fueled engine compared to mineral dieselfueled engine, especially in CI combustion mode. However these two fuels did not show any significant difference in NOx emissions during combustion modes and mode transitions.

Fang et al. [28] demonstrated HCCI/CI combustion mode switching by deploying an integrated starter generator (ISG) in a hybrid configuration. This technique resulted in smoother mode switching because ISG motor applied a compensating torque during mode transition and eliminated the IMEP fluctuations. However, this technique could not be implemented in production engines due to system complexity and lack of control over the combustion phasing. Wang [29] designed a robust hybrid non-linear control system for smooth coordination of variable nozzle turbocharger (VNT) and EGR to achieve the combustion mode switching. However, this technique involved many sub-systems, which hindered its applicability in production grade engines. Lack of control over the air-fuel ratio during mode transition was another critical parameter, which was not taken care in these approaches.

Researchers focused on suitable air-fuel ratio during mode switching to avoid excessive fluctuations in IMEP and to reduce HC emissions. This technique was based on fuel compensation strategy. Burton et al [30] and Busch et al. [31] emphasized on abrupt changes in power output and exhaust emissions, which was primarily because of difference in response time between air and fuel handling systems. They found that spikes in power output and exhaust emissions were highly dependent on mode switching direction such as from CI to PCCI or from PCCI to CI. They suggested that higher HC emissions during PCCI to CI transition were due to excessive charge dilution and lower air-fuel ratio. However excessive PRR and higher air-fuel ratio were the factors responsible for NOx peak during CI to PCCI mode transition (Figure 7). 


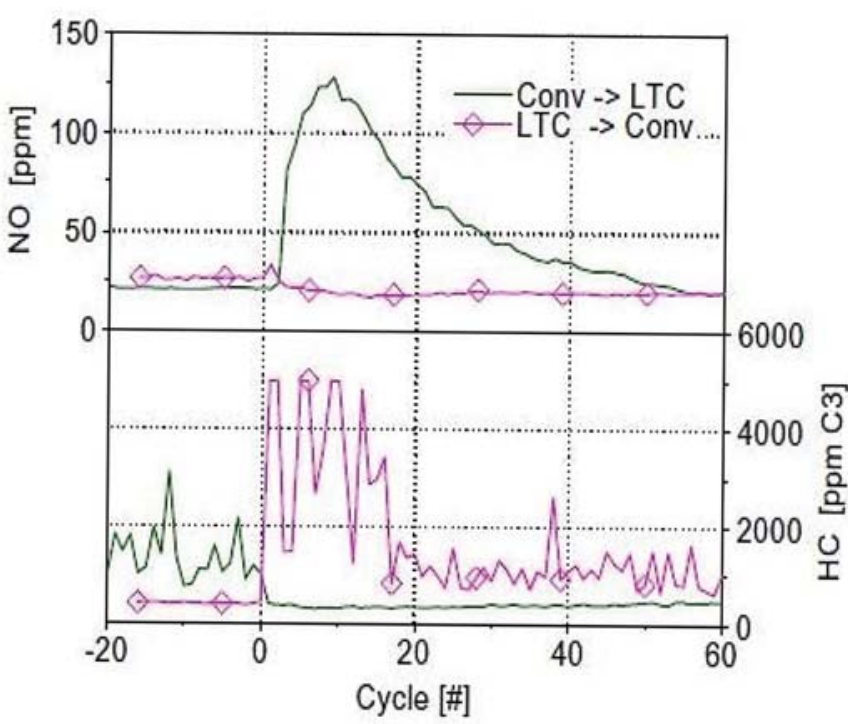

Figure 7: Non-transient mixed mode switches between LTC and conventional diesel combustion [30]

Slower response of air handling system is another major concern for mode switching. When combustion switches from one mode to other, fuel supply system adjusts the fuel parameters quickly however air supply system falls behind due to its inherently slower response time. To resolve this issue, Burton et al. [30] deployed an air charging system to provide right quantity of fresh air and EGR during the mode transition. Application of advanced charging methods such as variable geometry turbocharger (VGT) further reduced the $\mathrm{HC}$ emissions during mode transition by controlling the air-fuel ratio in order to reduce emissions during engine transients. Black et al. [32] and Hagena et al. [33] reported the effect of rate of mode transition (control parameters) on NOx emissions. They suggested that fast mode transition results in NOx peak. Tanabe et al. [34] also reported similar trend and suggested using appropriate fuel injection parameters and air management to suppress the NOx peak during mode transition.

In previous studies, fuel injection parameters have emerged as important control tools for smoother mode switching. Banerjee and Rutland [35] used multiple fuel injection strategy to reduce the excessive PRR due to charge stratification in order to study the effect of fuel injection parameters on mode switching. Han et al. [36] added another parameter as shorter path of EGR to mode switching strategy. They suggested that shorter path of EGR resulted in faster response for the air charging system, which reduced the NOx emissions. They emphasized on combination of appropriate fuel injection strategy and shorter path of EGR for effective mode transition. Kim et al. [37] developed a transient fuel injection strategy for mode switching and used lower injected fuel quantity at retarded SoI timings to reduce the IMEP fluctuations during mode transition. Similar investigations were also carried out by Rohani et al. [38] in a heavy-duty engine. Shi et al. [39] proposed another fuel injection strategy for reducing emissions during mode transition. They suggested that IMEP fluctuations and HC spikes were caused mainly by incomplete combustion during some mode transition cycles, which can be reduced by adding some extra fuel during early transitional cycles. This extra fuel will also be able to take care of slight drop in combustion efficiency during mode transition.

Few researchers also explored mode switching using external fuel-air mixture preparation technique [40]. They reported smoother combustion mode switching by installing an external fuel atomizer. However this technology was not adopted by subsequent researchers due to requirement of auxiliary instruments. Asad et al. [41] and Lu et al. [42] developed a mode switching algorithm for smoother mode transition. They used two fuel injection strategies as single injection LTC and multiple injection LTC, in order to avoid fluctuations in IMEP. They regulated the parameters through a closed loop control to achieve desired level of combustion and operational smoothness. However this system is required to be coupled with an in-cylinder pressure sensors, which makes this technique quite expensive for practical applications in practical production grade IC engines.

\section{Conclusions}

In last few decades, several LTC technologies have evolved and gained significant attention of engine researchers worldwide. Advancements in LTC technologies such as PCCI and RCCI combustion have made the LTC concept suitable for application in IC engines however few operational issues restrict full-scale application of LTC in production grade engines. This review article shows the potential of mode switching strategies, which can enable commercial application of LTC techniques in production grade engines. Using these strategies, an engine can be operated in LTC mode up to medium loads and then it can be switched to conventional combustion modes at higher engine loads by tweaking suitable operational parameters. Experimental studies have showed that emissions (NOx and particulates) were significantly lower in LTC mode and engine performance was quite similar to conventional combustion engines as well. Therefore, these techniques should be further evolved to take advantages of LTC for commercial applications such as vehicles. Use of mode switching technique for RCCI combustion and conventional CI combustion may be a new area of research and development at Industrial scale, to take benefits of features such as lower emissions, higher thermal efficiency and capability of utilization of a wide range of alternative fuels and low quality conventional fuels.

\section{References}

1. Agarwal AK, Singh AP, Maurya RK. Evolution, challenges and path forward for low temperature combustion engines. Progress in Energy and Combustion Science 2017; 61:1-56.

2. Akihama K, Takatori Y, Inagaki K, Sasaki S, Dean AM. Mechanism of the smokeless rich diesel combustion by reducing temperature. SAE Technical Paper 2001; 2001 01-0655.

3. Kook S, Bae C, Miles P, Choi D. The influence of charge dilution and injection timing on low-temperature diesel combustion and emissions. SAE Technical Paper 2005; 2005-01-3837.

4. Singh AP, Sharma N, Satsangi DP, Kumar V, Agarwal AK. Reactivity-controlled compression ignition combustion using alcohols. Chapter 2 in Advanced Engine Diagnostics, Springer Singapore, 2018. (ISBN \# 978-981-13-3274-6).

5. Onishi S, Jo SH, Shoda K, Jo PD, Kato S. Active thermo-atmosphere combustion (ATAC)-A new combustion process for internal combustion engines.SAE Technical Paper 1979; 790501.

6. Stanglmaier RH, Roberts CE. Homogeneous charge compression ignition (HCCI): benefits, compromise and future engine applications. SAE Technical Paper 1999; 1999-01-3682.

7. Maurya RK, Agarwal AK. Experimental investigation on the effect of intake air temperature and air-fuel ratio on cycle-to-cycle variations of HCCI combustion and performance parameters. Applied Energy 2011; 88(4):1153-1163.

8. Singh AP, Agarwal AK. Combustion characteristics of diesel HCCI engine: An experimental investigation using external mixture formation technique. Applied Energy 2012; 99:116-125.

9. Gan S, Kiat H, Kar N, Pang M. Homogeneous charge compression ignition (HCCI) combustion: implementation and effects on pollutants in direct injection diese engines. Applied Energy 2011; 88:559-567.

10. Dec JE, Kelly-Zion PL. The effects of injection timing and diluents addition on late-combustion soot burnout in a DI diesel engine based on simultaneous 2-D imaging of $\mathrm{OH}$ and soot. SAE Technical Paper 2000; 2000-01-0238.

11. Ryan III TW, Callahan TJ. Homogeneous charge compression ignition of diesel fuel. SAE Technical Paper 1996; 961160.

12. Singh G, Singh AP, Agarwal AK. Experimental investigations of combustion, performance and emission characterization of biodiesel fuelled HCCI engine using external mixture formation technique. Sustainable Energy Technologies and Assessments 2014; 6:116-128.

13. Jain A, Singh AP, Agarwal AK. Effect of split fuel injection and EGR on NOx and $\mathrm{PM}$ emission reduction in a low temperature combustion (LTC) mode diesel engine. Energy 2017; 122:249-264.

14. Jain A, Singh AP, Agarwal AK. Effect of fuel injection parameters on combustion stability and emissions of a mineral diesel fueled partially premixed charge compression ignition (PCCI) engine. Applied Energy 2017; 190:658-669.

15. Kokjohn SL, Reitz RD. Reactivity controlled compression ignition and conventional diesel combustion: a comparison of methods to meet light-duty NOx and fuel economy targets. Int J Engine Res 2013; 14(5):452-468.

16. Paykani A, Kakaee A, Rahnama P, Reitz RD. Progress and recent trends in reactivity-controlled compression ignition engines. Int J Engine Res 2016; 17(5):481-524.

17. Santoso H, Matthews J, Cheng WK. Managing SI/HCCI dual-mode engine operation. SAE Technical Paper 2005; 2005-01-0162.

18. Milovanovic N, Dave B, Gedge S. Cam profile switching and phasing strategy versus fully variable valve train strategy for transitions between spark ignition and controlled auto ignition modes. SAE Technical Paper 2005; 2005-01-0766.

19. Zhang Y, Xie H, Zhao H. Investigation of SI-HCCI hybrid combustion and control strategies for combustion mode switching in a four-stroke gasoline engine. Combust. Sci. and Tech. 2009; 181(5):782-799.

20. Tian G, Wang Z, Wang J. Effects of key factors on the engine combustion mode 
switching between HCCI and SI. J Eng Gas Turb Power. 2009; 131(1): 0128031-012803-8.

21. Kuboyama T, Moriyoshi Y, Hatamura K. A study of control strategy for combustion mode switching between HCCI and SI with the blow down supercharging system. SAE Technical Paper 2012; 2012-01-1122.

22. Manofsky L, Vavra J, Assanis DN, Babajimopoulos A. Bridging the gap between HCCI and SI: Spark-assisted compression ignition. SAE Technical Paper 2011; 2011-01-1179.

23. Polovina D, McKenna D, Wheeler J, Sterniak J, Miersch-Wiemers O, Mond A, et al. Steady-state combustion development of a downsized multi-cylinder engine with range extended HCCI/SACI capability. SAE Int J Engines 2013; 6(1):504519

24. Zhou L, Hua J, Wei H, Dong K, Feng D, Shu G. Knock characteristics and combustion regime diagrams of multiple combustion modes based on experimental investigations. Applied Energy 2018; 229:31-41.

25. Narayanaswamy K, Rutland C. A modeling investigation of combustion control variables during DI-diesel HCCI engine transients. SAE Technical Paper 2006; 2006-01-1084.

26. Singh AP, Bajpai N, Agarwal AK. Combustion mode switching characteristics of a medium-duty engine operated in compression ignition/PCCI combustion modes. J. Energy Resour. Technol. 2018; 140(9):092201-092201-11.

27. Singh AP, Agarwal AK. CI/PCCI combustion mode switching of diesohol fuelled production engine. SAE Technical Paper 2017; 2017-01-0738.

28. Fang FY, Ouyang M, Gao G, Chen L. Combustion mode switching control in a HCCI diesel engine. Applied Energy 2013; 110:190-200.

29. Wang JM. Hybrid robust air-path control for diesel engines operation conventional and low temperature combustion and conventional diesel combustion modes. IEEE Trans Control System Technology 2008; 16:1138-51.

30. Burton J, Williams D, Glewen W, Andrie M. Investigation of transient emissions and mixed mode combustion for a light duty diesel engine. SAE Technical Paper 2009; 2009-01-1347.

31. Busch S, Bohac SV, Assanis DN. A study of the transition between lean conventional diesel combustion and lean, premixed, low-temperature diesel combustion. Journal of Engine Gas Turbine Power. 2008; 130:052804-8.
32. Black J, Eastwood PG, Tufail K, Winstanley T, Hardalupas Y, Taylor AMKP. Intercorrelations between smoke opacity, legal particulate sampling (LPS) and TEOM, during transient operation of a diesel engine. SAE Technical Paper 2007; $2007-$ 01-2060.

33. Hagena JR, Filipi ZS, Assanis DN. Transient diesel emissions: Analysis of engine operation during a tipin. SAE Technical Paper 2006; 2006-01-1151.

34. Tanabe K, Komatsu F, Nakayama S. A study on mode transition control between PCI and conventional combustion in a diesel engine. Int J Engine Res 2011; 12(1):69-86.

35. Banerjee S, Rutland C. Numerical investigation of high powered diesel mode transition using large eddy simulations. SAE Technical Paper 2012; 2012-01 0693.

36. Han S, Kim H, Bae C. Strategy for mode transition between low temperature combustion and conventional combustion in a diesel engine. SAE Technical Paper 2013; 2013-24-0058.

37. Kim K, Han S, Bae C. Mode transition between Low Temperature Combustion and Conventional Combustion with EGR and injection modulation in a diesel engine. SAE Technical Paper 2011; 2011-01-1389.

38. Rohani B, Park S, Bae C. Effect of injection strategy on low temperature conventional diesel combustion mode transition. SAE Technical Paper 2015; 201501-0836.

39. Shi L, Hu W, Deng K. Effects of fuel compensation in transitional cycles on the smoothness of combustion mode switching in a diesel engine. Fuel Processing Technology 2014; 118:55-63.

40. Canova M, Chiara F, Cowgill J. Experimental characterization of mixed-mode HCCI/ DI combustion on a common rail diesel engine. SAE Technical Paper 2007; 200724-0085.

41. Asad U, Divekar P, Chen X, Zheng M. Mode Switching Control for Diesel Low Temperature Combustion with Fast Feedback Algorithms. SAE Technical Paper 2012; 2012-01-0900.

42. Lu XC, Han D, Huang Z. Fuel design and management for the control of advanced compression-ignition combustion modes. Progress in Energy and Combustion Science. 2011; 37, 741-783. 